\title{
Welfare Perceptions of Public Expenditure on Environmental and Non-Environmental Goods
}

\author{
Qiyan Ong, Euston Quah* \\ Division of Economics, Nanyang Technological University, Singapore \\ Email: "ecsquahe@ntu.edu.sg
}

Received 26 February 2014; revised 30 March 2014; accepted 2 May 2014

Copyright (C 2014 by authors and Scientific Research Publishing Inc.

This work is licensed under the Creative Commons Attribution International License (CC BY). http://creativecommons.org/licenses/by/4.0/

(c) (i) Open Access

\begin{abstract}
Increasing research shows that income growth has a less than substantial impact on people's well-being. In contrast, environmental factors are found to have non-negligible impact on people's well-being. The research raises the question of whether more can be done to improve the wellbeing of the public through government spending on the environment. We conducted pair comparison surveys using the variance stable rank method on preferences for public expenditure on education, environment and transportation in Singapore. Both aggregate preference rankings as well as rank ordered logitregression analysis on individuals' rankings reveal that respondents perceive larger improvements in well-being from increasing public expenditure on environment goods compared to an equivalent increase in public expenditure on education goods.
\end{abstract}

\section{Keywords}

\section{Well-Being, Environmental Goods, Public Spending}

\section{Introduction}

There is increasing evidence which shows that despite enjoying substantial growth in national income, countries, especially developed countries with high per capita income, do not experience corresponding rise in reported levels of well-being [1]-[4]. If private income growth or growth in private consumption does not make people better off, it raises the question of whether more public spending, in particular, spending on non-consumption goods such as on the environment, is the key to improving public well-being [5] [6]. This might be the case when increasing environmental goods, such as clean air and water, are perceived to raise quality of life [7].

\footnotetext{
"Corresponding author.
} 
Indeed, other cross country comparison studies on public well-being have found that environmental factors, such as urban air pollution and extreme weather, have a considerable negative effect on countries' well-being [8]-[10]. However, as governments around the world prioritize economic growth over other quality of life measures as an indicator of well-being, public expenditure on the environment has been traditionally given lower priority than public expenditure on areas which are pertinent to economic growth. This phenomenon remains even as countries develop and enjoy high per capita income. Therefore, we ask whether and to what extent are government priorities on spending on the environment consistent with the contribution of environmental improvements to the well-being of the public.

To address this question, public perceptions of the marginal returns to well-being from environmental improvements as well as other public expenditure items have to be obtained and compared to actual expenditure. We obtained public perceptions of the marginal returns to well-being from different categories of public expenditure items through a paired comparison survey. Public perceptions of the importance of environmental goods to their well-being are measured against two other classes of public expenditure: education and transportation. Education and transportation spending are chosen because education spending represents human capital investment while transportation spending represents infrastructure investment, both of which are critical to economic growth.

The paired comparison method is chosen over other methods because it comprises features of both stated preferences and revealed preferences. It requires survey respondents to make binary choices between pairs of public spending items (stated preferences), which is cognitively easier for survey respondents compared to a direct comparison of a range of items. From the binary choices, we can then derive individuals' preference orders for the range of goods [11], hence revealing individuals' preferences and priorities. Our survey includes two items from each of the three classes of public expenditure (environment, education and transportation) and respondents are required to compare pairs of public expenditure items within and across the three categories. If the environment contributes little to people's well-being compared to consumables which could also contribute to economic growth, we ought to observe that environmental goods would be consistently ranked lower by the public, compared to public expenditure on education and transportation.

For the paired comparison survey to be informative to policy, it is important to determine how sensitive people's choices are to different measures of well-being. Hence, we contrast public perceptions of the importance of different types of public expenditure to two existing measures of well-being-life happiness and life satisfaction. Psychologists define happiness as a measure of the emotive state of an individual's well-being and life satisfaction as the individual's global cognitive evaluation of her life based on some subjective criteria of what constitutes an ideal life [12] [13]. The differences in the two measures of well-being are reflected in their imperfect correlation of approximately 0.5 [14]. Since happiness is entirely based on an individual's emotions while life satisfaction involves value judgment, it is plausible that compared to happiness, individuals are more likely to choose environmental goods over other classes of public expenditure items when life satisfaction is the criterion of evaluation as the environmental goods in our survey represent environmental conservation efforts which benefit future generations rather than the present.

We conducted our paired comparison survey in Singapore where only $1.3 \%{ }^{1}$ of Singapore's total budget is allocated to environmental improvements. We have two main findings. First, survey respondents display welldefined preferences for public expenditure items, suggesting that the paired comparison survey may be useful for elicitation of public perceptions. Second, we find that environmental goods are consistently ranked higher than at least one item from another class of public expenditure. This implies that people do not perceive that spending on the environment always brings about the least (lowest) improvement in the public's well-being.

The next section describes our survey design. Section 3 discusses the empirical approach used in our analyses. The survey data are described in Section 4 and the analyses and results are presented in Section 5 . The last section concludes.

\section{Survey Design}

Respondents are asked in the survey to make binary choices between pairs of public expenditure items with the information that the government has a fixed amount of budget to be spent on only one of the public expenditure items. For each pair of public expenditure items, respondents are asked to choose which of public expenditure

${ }^{1}$ Figure is obtained from Singapore’s Budget Highlights 2013. 
items will contribute more to their well-being. No ties are allowed in the paired comparisons. We contrast two common measures of subjective well-being in two separate surveys-happiness and life satisfaction. The exact wording of the question asked in the final survey is:

"Suppose that the Government has 100 million Singapore dollars to spend on the improvement on one governmental budget item. For each pair of government budget items listed below, please choose the item that will contribute more to your life satisfaction (happiness)".

Our final survey consists of six public expenditure items, two items from each of the three categories of public expenditure- education, transportation and environment. The final list of survey questions used in Singapore is provided in Table 1. Previous studies have shown that survey responses are susceptible to how questions are framed [15]. In particular, individuals are loss averse and prefer choices which reduce their potential losses rather than choices which are improvements over their status quo. To prevent the confounding effect of loss aversion from influencing individuals' choices for a particular category of public expenditure, for each category of public expenditure, we framed one item as a "gain" and the other a "reduction in loss".

\section{Methodology}

The survey adopts the paired comparison method which requires respondents to make binary choices between pairs of items selected from a list of items of interest. Through the choices that the respondents made, it is not only possible to derive an individual's ranking of the set of items but also the aggregate ranking of the set of items as a group. Paired comparisons avoid the problem of embedding [16] and anchoring [17] associated with contingent valuation, and are superior to other stated preference methods because of its relative ease in comparing two items rather than multiple items at each time [11]. This method has been used extensively in the construction of damage schedules for environmental goods by further allowing survey respondents to make binary choices between environment goods and sums of money [18]-[20]. Although paired comparison surveys have been used mostly in the comparison of environment items, Brown et al. [21] showed that there is high reliability for public good choices which involves comparison of environmental and non-environmental goods.

From the choices that respondents made, a respondent's ranking of a set of items can be derived from her preference score for each item, which is the number of times she prefers that item over the other items in the choice set. Each item will have a maximum score of $(n-1)$ where $n$ is the total number of items in the choice set. When there is no circular triad, or inconsistent choices, the individual preference profile contains all integers from 0 to $n-1$. Circular triads cause some integers to appear more than once in the preference profile and others to disappear [11]. Since paired comparison does not allow for an "indifferent choice", whenever random intransitivity results in the same preference score for two items, indifference between the two items is assumed [22]. The item with the highest preference score is given the highest rank in the individual's preference order. When two items have the same preference score, they share the same rank. Individual's ranking can then be analysed using rank ordered logit regressions to identify the differences in preference orders of individuals with different

Table 1. List of environmental and non-environmental public items and their descriptions in the Singapore survey.

\begin{tabular}{|c|c|c|}
\hline Class of Public Items & Gains/Reduction in Losses & List of Public Items That Appear in the Final Surveys \\
\hline \multirow[b]{2}{*}{ Education } & Gain & $\begin{array}{l}\text { Increase the variety of subjects, courses or academic programs available to } \\
\text { tertiary students }\end{array}$ \\
\hline & Reduction in Loss & $\begin{array}{l}\text { Reduce failure and dropout rates through increasing remedial lessons for } \\
\text { academically weaker students and improving monitoring system to help } \\
\text { teachers track the development of students in primary and secondary schools }\end{array}$ \\
\hline \multirow[b]{2}{*}{ Transportation } & Gain & Expand the MRT network to more housing estates \\
\hline & Reduction in Loss & $\begin{array}{l}\text { Reduce waiting time for buses by implementing more efficient central } \\
\text { planning of bus network }\end{array}$ \\
\hline \multirow[t]{2}{*}{ Environment } & Gain & $\begin{array}{l}\text { Increase the amount of waste recycled by having more and bigger recycling } \\
\text { bins, recycling more electronic waste and researching on more efficient } \\
\text { recycling techniques }\end{array}$ \\
\hline & Reduction in Loss & $\begin{array}{l}\text { Reduce carbon emissions in the air by investing in alternative energies such } \\
\text { as solar power }\end{array}$ \\
\hline
\end{tabular}


socioeconomic characteristics.

Aggregate or collective rankings of a set of items can also be derived from the paired comparisons. A simple way to summarize the individuals' preferences derived from paired comparisons is the variance stable rank method [23]. By aggregating the preference scores of all individuals and comparing the proportion of times each item is chosen over another item relative to the maximum number of times it is possible to be chosen by all individuals, the aggregate scale values and in turn the collective ranks of each item can be derived. Moreover, the cardinal nature of aggregate scale values makes them more informative than simple ranks and, near close aggregate scale values suggest that the population may actually be indifferent towards two items and the scale values reflect random errors in responses. In contrast, distinct aggregate scale values suggest strict preference of one item over the other in the aggregate.

\section{Data Description}

Random sampling was used throughout the study to obtain samples. Surveys were conducted at different parts of the cities, such as residential estates, shopping and business districts ${ }^{2}$. The survey is self-administered by the respondent with the aid of an interviewer. There were 500 survey respondents, half of which were asked to base their responses on the impact that the listed public expenditure has on their life satisfaction while the other half were asked to based their responses on the impact that the listed public expenditure has on their happiness. The surveys were administered in English.

The socioeconomic characteristics of the respondents in the Singapore sample are presented in Table 2. The tables show that our sample of respondents is representative of the Singapore population in terms of most socioeconomic characteristics with the key exception of education level. Approximately half of our respondents have university degrees, while only $26 \%$ of the population in Singapore completed university education ${ }^{3}$. Hence, our sample is biased towards the educated residents.

We compute the average coefficient of consistency, the proportion of answers without circular triads, to test if respondents gave answers consistent with well-defined preferences. The coefficient approaches one if there are no circular triads in a person's choice [11]. We find that respondents have well-defined preferences over the paired comparison questions, with high average coefficient of consistency in both sets of survey, happiness (coefficient of consistency $=0.790$ ) or life satisfaction (coefficient of consistency $=0.758$ ). This gives us confidence that our respondents take the paired comparison survey seriously and their responses are reliable representation of their preferences.

\section{Results}

Table 3 summarizes the respondents' aggregate preferences of the six public expenditure items. Regardless of the measure of well-being used, we find that a transportation item is ranked first and an education item is ranked last. The substantial difference between the scale values of these two items (life satisfaction: 36 points difference; happiness: 33 points difference) reveals that there are distinguishable perceived marginal returns in well-being from different public expenditure items. On the other hand, the differences in the scale values of items in the middle ranks are much smaller, suggesting greater heterogeneity in people's perception towards these items. There is also some evidence of loss aversion as people tend to prefer items which are framed as "reduction in losses” rather than gains.

Using the rank and scale value information, what can we conclude about the relative importance of environmental goods and non-environmental goods to people's well-being? While environmental items are not ranked first, environmental items have an average rank of 3 when respondents made their choices based on life satisfaction and an average rank of 3.5 when respondents made their choices based on life happiness. In relation to other public expenditure categories, the ranks reveal that environmental items are on average preferred to education items (average rank in life satisfaction survey: 4.5; average rank in happiness: 5) regardless of the well-being measure used. On the other hand, transportation items score the same average rank of 3 as environmental items when respondents made their choices based on life satisfaction and a higher average rank of 2 when respondents

\footnotetext{
${ }^{2}$ Interviewers were sent to two locations in the East, West, North, South and Central part of Singapore. The interviewers were stationed at a shopping mall, MRT stations, bus depots or open areas with high human traffic during lunch hours or weekends and invited passers-by to participate in the survey.

${ }^{3}$ Figure is obtained from Singapore Census 2010.
} 
Table 2. Summary statistics of the Singapore sample.

\begin{tabular}{ccccc}
\hline Variable & Observations & Sample Mean & S.D & Population Mean \\
\hline Male & 500 & 0.536 & 0.499 & 0.507 \\
Age & 500 & 36.786 & 10.282 & 37.400 \\
Has at Least One Schooling Child & 500 & 0.356 & 0.479 & $0.322^{\mathrm{a}}$ \\
University Degree & 500 & 0.468 & 0.499 & 0.228 \\
Employed & 500 & 0.842 & 0.365 & 0.959 \\
High Personal Income (SGD 6000 and Above) & 500 & 0.146 & 0.353 & 0.138 \\
Malay & 500 & 0.082 & 0.274 & 0.134 \\
Indian & 500 & 0.108 & 0.310 & 0.092 \\
\hline
\end{tabular}

${ }^{a}$ Figure reflects the proportion of the households with children aged 15 or below. Note: data about the population is obtained from the Census Report 2010 and the Report on Labor Force in Singapore 2010.

Table 3. Simple ranking of environmental and non-environmental public expenditure items in Singapore.

\begin{tabular}{cccccc}
\hline \multirow{2}{*}{$\begin{array}{c}\text { Category of Public } \\
\text { Expenditure Items }\end{array}$} & Public Expenditure Items & \multicolumn{2}{c}{ Life Satisfaction } & \multicolumn{2}{c}{ Happiness } \\
\cline { 3 - 6 } Transport & Reduce waiting time & 1 & Scale Value & Rank & Scale Value \\
Environment & Reduce carbon emissions & 2 & 51.8 & 1 & 61.6 \\
Education & Reduce failure and dropout rates & 3 & 49.4 & 2 & 4 \\
Environment & Increase waste recycled & 4 & 49 & 5 & 50.7 \\
Transport & Expand the MRT network & 5 & 48.3 & 3 & 51 \\
Education & Increase the variety of subjects & 6 & 35.8 & 6 & 38.6 \\
\hline
\end{tabular}

made their choices based on life happiness. Since the scale values of transportation items are larger than the environmental items, the results suggest that on average, respondents perceive transportation items to have a larger impact on their well-being than environmental items.

Table 4 presents the rank ordered logit regression results of the six public expenditure items. The results show that on average, people perceive larger marginal returns to well-being from spending more on environmental items than education items. The preference for environmental items to education items is stable across different evaluation criteria used (happiness or life satisfaction).

However, perceptions of the relative importance of environmental spending to education spending vary by demographic characteristics. However, perceptions of the relative importance of environmental spending to education spending vary by demographic characteristics. In particular, in Singapore, the odds that an individual will choose environment items over education items are higher if she has high personal income. This suggests that there are club goods in Singapore which high income earners can take advantage of, but not low income earners, which induces even stronger preference for environmental spending among the high income earners. As expected, respondents in Singapore with schooling children are less likely to choose environment items over education items compared to respondents without schooling children. Finally, perceptions of relative importance of environmental and education spending also differs across ethnicity in Singapore. Malay and Indian respondents in Singapore are less likely to choose environment items over educational items compared to Chinese respondents. We believe that education spending is more important for these racial groups because the passing rate for school leaving examinations in primary and secondary schools is lower for these racial groups ${ }^{4}$.

\footnotetext{
${ }^{4}$ Performances in school leaving examinations in Singapore can be obtained from http://www.moe.gov.sg/media/press/2010/12/performance-by-ethnic-group-2000-2009.php.
} 
Table 4. Rank-ordered logit estimates and odds of individual ranking of public expenditure items in Singapore.

\begin{tabular}{|c|c|c|}
\hline Variables & Coefficient & Odds \\
\hline Environment & $0.767^{* * *}$ & 2.154 \\
\hline Transportation & 0.469 & 1.598 \\
\hline Gains & -0.214 & 0.807 \\
\hline Environment $\times$ Happiness & -0.154 & 0.858 \\
\hline Transport $\times$ Happiness & 0.028 & 1.028 \\
\hline Gain $\times$ Happiness & 0.097 & 1.102 \\
\hline Environment $\times$ Male & $-0.218^{*}$ & 0.804 \\
\hline Transport $\times$ Male & -0.068 & 0.934 \\
\hline Gain $\times$ Male & 0.110 & 1.116 \\
\hline Environment $\times$ Age & 0.001 & 1.001 \\
\hline Transport $\times$ Age & 0.006 & 1.006 \\
\hline Gain $\times$ Age & 0.002 & 1.002 \\
\hline Environment $\times$ Child & $-0.620^{* * *}$ & 0.538 \\
\hline Transport $\times$ Child & $-0.596^{* * *}$ & 0.551 \\
\hline Gain $\times$ Child & -0.082 & 0.921 \\
\hline Environment $\times$ Employed & -0.076 & 0.927 \\
\hline Transport $\times$ Employed & 0.078 & 1.082 \\
\hline Gain $\times$ Employed & $-0.192^{* *}$ & 0.825 \\
\hline Environment $\times$ Employed $\times$ High Income & $0.401^{* *}$ & 1.493 \\
\hline Transport $\times$ Employed $\times$ High Income & 0.165 & 1.180 \\
\hline Gain $\times$ Employed $\times$ High Income & -0.099 & 0.906 \\
\hline Environment $\times$ Malay & $-0.621^{* * *}$ & 0.537 \\
\hline Transport $\times$ Malay & $-0.533^{* *}$ & 0.587 \\
\hline Gain $\times$ Malay & $-0.323^{* * *}$ & 0.724 \\
\hline Environment $\times$ Indian & $-0.335^{*}$ & 0.715 \\
\hline Transport $\times$ Indian & $-0.469^{* *}$ & 0.626 \\
\hline Gain $\times$ Indian & 0.008 & 1.008 \\
\hline
\end{tabular}

Notes: robust standard errors in parentheses. ${ }^{* * *} \mathrm{p}<0.01,{ }^{* *} \mathrm{p}<0.05,{ }^{*} \mathrm{p}<0.1$

\section{Conclusions}

Governments around the world have consistently relied on income growth as the indicator of quality of life in their countries. However, there is substantial evidence which suggests that residents in countries with high per capita income or high income growth are not necessarily happier or more satisfied with their lives. Since growth in private income, and in turn private spending, does not appear to improve well-being of the people, $\mathrm{Ng}$ (2001, 2008) suggests that public spending should play a larger role in improving the well-being of the people. Our study uses a paired comparison study to compare people's perception of the welfare effects of different categories of public expenditure in a developed city with high per capita income. We find that respondents responded 
well to the paired comparison method and their preferences are well-elicited. The paired comparison method not only allows us to aggregate people's preferences of public expenditure items but also reveals the heterogeneity in people's preferences.

Our results reveal that while the budget for environmental spending is the smallest compared to transportation and education spending, it may not yield the smallest welfare returns. In aggregate, residents in Singapore perceive higher marginal gains in well-being from further expenditure on environmental improvements compared to education improvements. This preference remains when we compare the preferences of high income earners to low income earners at an individual level. Our findings suggest that as people's income increases and could afford private consumption of public expenditure items such as education, increasing public expenditure in areas where private consumption is limited such as the environment may be warranted. Hopefully, the findings here have the use for public policy decision-making involving the provision of types of public goods and their relationship to welfare generation for society.

\section{References}

[1] Diener, E., Diener, M. and Diener, C. (1995) Factors Predicting the Subjective Well-Being of Nations. Journal of Personality and Social Psychology, 69, 851-864. http://dx.doi.org/10.1037/0022-3514.69.5.851

[2] Easterlin, R. (1974) Does Economic Growth Improve the Human Lot? Some Empirical Evidence” In: David, R. and Reder, R., Eds., Nations and Households in Economic Growth: Essays in Honor of Moses Abramovitz, Academic Press, New York.

[3] Easterlin, R.A. (2005) A Puzzle for Adaptive Theory. Journal of Economic Behavior and Organization, 56, 513-521. http://dx.doi.org/10.1016/j.jebo.2004.03.003

[4] Oswald, A.J. (1997) Happiness and Economic Performance. Economic Journal, 107, 1815-1831. http://dx.doi.org/10.1111/j.1468-0297.1997.tb00085.X

[5] Ng, Y.K. (2001) Is Public Spending Good for You? World Economics, 2, 1-17.

[6] Ng, Y.K. (2008) Environmentally Responsible Happy Nation Index: Towards an Internationally Acceptable National Success Indicator. Social Indicators Research, 85, 425-446. http://dx.doi.org/10.1007/s11205-007-9135-1

[7] Quah, E. and Tan, K.C. (2002) Siting Environmentally Unwanted Facilities: Risks, Trade-Offs and Choices. Edward Elgar Publishers, Aldershot.

[8] Welsch, H. (2002) Preferences over Prosperity and Pollution: Environmental Valuation Based on Happiness Surveys. Kyklos, 55, 473-494. http://dx.doi.org/10.1111/1467-6435.00198

[9] Welsch, H. (2006) Environment and Happiness: Valuation of Air Pollution Using Life Satisfaction Data. Ecological Economics, 58, 801-813. http://dx.doi.org/10.1016/j.ecolecon.2005.09.006

[10] Rehdanz, K. and Maddison, D. (2005) Climate and Happiness. Ecological Economics, 52, 111-125. http://dx.doi.org/10.1016/j.ecolecon.2004.06.015

[11] Peterson, G. and Brown, T. (1998) Economic Valuation by the Method of Paired Comparison, with Emphasis on Evaluation of the Transitivity Axiom. Land Economics, 74, 240-261. http://dx.doi.org/10.2307/3147054

[12] Shin, D. and Johnson, D. (1978) Avowed Happiness as an Overall Assessment of the Quality of Life. Social Indicators Research, 5, 475-492. http://dx.doi.org/10.1007/BF00352944

[13] Compton, W.C. (2005) An Introduction to Positive Psychology. Thomson Wadsworth, Belmont.

[14] Suh, E., Diener, E., Oishi, S. and Triandis, H. (1998) The Shifting Basis of Life Satisfaction Judgments across Cultures: Emotions versus Norms. Journal of Personality and Social Psychology, 74, 482-493. http://dx.doi.org/10.1037/0022-3514.74.2.482

[15] Kahneman, D., Knetsch, J. and Thaler, R. (1991) The Endowment Effect, Loss Aversion, and Status Quo Bias. Journal of Economic Perspectives, 5, 193-206. http://dx.doi.org/10.1257/jep.5.1.193

[16] Kahneman, D. and Knetsch, J. (1992) Valuing Public Goods: The Purchase of Moral Satisfaction. Journal of Environmental Economics and Management, 22, 57-70. http://dx.doi.org/10.1016/0095-0696(92)90019-S

[17] Boyle, K., Bishop, R. and Welsh, M. (1985) Starting Point Bias in Contingent Valuation Bidding Games. Land Economics, 61, 188-196. http://dx.doi.org/10.2307/3145811

[18] Rutherford, M., Knetsch, J. and Brown, T. (1998) Assessing Environmental Losses: Judgments of Importance and Damage Schedules. Harvard Environmental Law Review, 20, 51-101.

[19] Chuenpagdee, R., Knetsch, J. and Brown, T. (2001) Costal Management Using Public Judgments, Importance Scales, and Predetermined Schedules. Coastal Management, 29, 253-270. http://dx.doi.org/10.1080/089207501750475091 
[20] Quah, E., Choa, E. and Tan, K.C. (2006) Use of Damage Schedules in Environmental Valuation: The Case of Urban Singapore. Applied Economics, 38, 1501-1512. http://dx.doi.org/10.1080/00036840500399842

[21] Brown, T., Kingsley, D., Peterson, G., Flores, N., Clarke, A. and Birjulin, A. (2008) Reliability of Individual Valuations of Public and Private Goods: Response Time, Preference Learning, and Choice Consistency. Journal of Public Economics, 92, 1595-1606. http://dx.doi.org/10.1016/j.jpubeco.2008.01.004

[22] Loomis, J., Peterson, G., Champ, P., Brown, T. and Lucero, B. (1998) Paired Comparison Estimates of Willingness to Accept versus Contingent Valuation Estimates of Willingness to Pay. Journal of Economic Behaviour \& Organization, 35, 501-515. http://dx.doi.org/10.1016/S0167-2681(98)00050-X

[23] Dunn-Rankin, R. (1983) Scaling Methods. Lawrence Erlbaum Associates, Lawrence. 